\title{
Impacto do Programa de Reestruturação dos Hospitais de Ensino no âmbito do SUS em um hospital do Ceará
}

I ${ }^{1}$ Denise Lima Nogueira, ${ }^{2}$ Márcia Maria Tavares Machado, ${ }^{3}$ Geison Vaconcelos Lira I

Resumo: Com o objetivo de avaliar o desempenho de um hospital do interior do Estado do Ceará nos eixos normativos do Programa de Reestruturação dos Hospitais de Ensino após a contratualização com o Sistema Único de Saúde, foi realizada uma pesquisa avaliativa, descritiva e exploratória, com abordagem qualitativa, pautada na Avaliação de Quarta Geração de Guba e Lincoln (1989), no período de novembro de 2014 a maio de 2015. Esta pesquisa seguiu sete dos 12 passos propostos pelo círculo hermenêutico dialético, teve como sujeitos 33 respondentes, os quais foram divididos em cinco círculos hermenêutico-dialéticos. A análise dos dados foi realizada a partir da técnica de comparação constante, por meio da Teoria Fundamentada dos Dados e organizada a partir dos eixos normativos de hospitais de ensino e dos organizadores da Avaliação de Quarta Geração. Os resultados evidenciaram mudanças relativas aos três eixos normativos dos hospitais de ensino, com melhorias nos eixos "Gestão, Ensino e Pesquisa” e "Modelo de Alocação de Recursos Financeiros", preocupaçôes nos eixos "Ações Estratégicas na Área da Assistência" e "Gestão, Ensino e Pesquisa" e questôes não consensuadas no eixo "Açôes Estratégicas na Área da Assistência".

> Palavras-chave: Hospitais de ensino. Avaliação. Método.

\author{
${ }^{1}$ Universidade Federal do \\ Ceará. Fortaleza-CE, Brasil \\ (deniseln2009@hotmail.com). \\ ORCID: 0000-0002-4036-6096 \\ ${ }^{2}$ Universidade Federal do \\ Ceará. Fortaleza-CE, Brasil \\ (marciamachadoufc@gmail.com). \\ ORCID: 0000-0002-0149-5792 \\ ${ }^{3}$ Universidade Federal do Ceará. \\ Fortaleza-CE, Brasil (vasconlira@ \\ gmail.com). \\ ORCID: 0000-0001-7623-0652
}

Recebido em: 09/03/2019 Aprovado em: 25/03/2020 Revisado em: 14/10/2021 


\section{Introdução}

A Constituição Federal de 1988, ao passo que cria o Sistema Único de Saúde (SUS) como o sistema que regula a saúde pública brasileira, afirma no Artigo 196 que esta é direito de todos e dever do Estado, também determina no Artigo 200, inciso III, que compete a este sistema ordenar a formação de recursos humanos na área de saúde (BRASIL, 1998).

No contexto da assistência e formaçáo na e para a saúde, os Hospitais de Ensino (HE) são relevantes por configurarem Hospitais Gerais e/ou Especializados, que além de prestarem assistência à saúde são campo de prática para atividades curriculares de cursos da área da saúde de propriedade de uma Instituição de Ensino Superior (IES), pública ou privada, ou formalmente conveniados a esta (BRASIL, 2004a). Nesse sentido, são responsáveis pela formação de profissionais da saúde que atuarão na rede básica e nos hospitais públicos e privados (BITTAR, 2004).

De acordo com Brasil (2007), compete aos Hospitais de Ensino participar das políticas prioritárias do SUS e "colaborar ativamente na constituição de uma rede de cuidados progressivos à saúde, estabelecendo relaçôes de cooperação técnica no campo da atenção e da docência com a rede básica, de acordo com as realidades locorregionais".

No Brasil, durante os anos 70 já se propunham estratégias para aproximar a educação médica do sistema de saúde, das quais pode-se citar a assinatura do Convênio MEC-MPAS, denominado Convênio Global, que envolvia tanto internação como atendimento ambulatorial. Todavia, os hospitais de ensino foram caracterizados somente em 1991, meados a período de crise financeira, a partir Fator de Incentivo ao Desenvolvimento do Ensino e da Pesquisa Universitária (FIDEPS) como estratégia para "apoiar o desenvolvimento da infraestrutura necessária ao desenvolvimento de ensino e pesquisa” nesses nosocômios Nesta época, foram definidos como hospitais de ensino aqueles reconhecidos pelo Ministério da Educação como centro de referência nacional no Sistema Integrado de Procedimentos de Alta Complexidade e com funcionamento regular de no mínimo cinco anos (MACHADO e KUCHENBECKER, 2007).

Em 2003, dada a necessidade de reforma da assistência hospitalar no Brasil e a complexidade organizacional e de financiamento dos hospitais de ensino, os Ministérios da Saúde e da Educaçáo instituíram uma Comissão Interistitucional, formada por representatividade dos segmentos da Educação, da Saúde, do 
Planejamento, do Orçamento e Gestão, e da Ciência e Tecnologia, a qual tinha como objetivo avaliar e diagnosticar a situação dos Hospitais Universitários e de Ensino, visando reorientar e/ou formular a política nacional para o setor (BRASIL, 2004a; BRIZOLA, 2010; PARPINELLY, 2015).

Destarte, em 2004, os Ministérios da Educação e da Saúde definiram, mediante as Portarias Interministeriais no 1.000 e 1.005 de 2004, os critérios de certificação dos Hospitais de Ensino que culminaram no lançamento da Portaria $n^{\circ} 1.702$ de 2004 que criou o Programa de Reestruturação dos Hospitais de Ensino no âmbito do SUS (GALANTE et al, s/d).

Este programa emergiu como uma proposta de reestruturar a política do setor frente à necessidade de integrar a rede dos serviços de saúde, considerando o papel estratégico dos HE na assistência, na formação de profissionais e no desenvolvimento tecnológico (BRASIL, 2004b).

Logo, para ser certificada como Hospital de Ensino, a unidade hospitalar deve ser atender aos requisitos dispostos na Portaria Interministerial no 1.000 de 2004 e, de acordo com a Portaria no 1.702/2004, as açôes estratégicas dessas unidades hospitalares no âmbito da assistência, pesquisa e desenvolvimento tecnológico, educação permanente e formação profissional e gestão hospitalar devem ser definidas e especificadas no processo de contratualização entre o representante legal do hospital de ensino e o gestor do SUS (BRASIL, 2004a; BRASIL, 2004b). No $\mathrm{HE}$, devem estar estabelecidas as metas quantitativas e qualitativas do processo de atenção à saúde, de ensino e pesquisa e de gestáo hospitalar, sob acompanhamento e constatação do Conselho Gestor da Instituição ou Comissão Permanente de Acompanhamento de Contratos (BRASIL, 2004b).

Desta forma, o modelo de alocação de recursos financeiros para a atenção à saúde, gestão, ensino e educação de pesquisa proposto para o custeio dos Hospitais de Ensino foi o de orçamentação mista, composto por componente com valor fixo mensal, componente com valor variável a partir do cumprimento de metas estabelecidas e componente correspondente à produção de serviços (BRASIL, 2004b). Esse modelo objetivou promover mudanças na gestáo hospitalar e na gestão da saúde, que "passa a ser orientada por resultados e desempenhos e não apenas por procedimentos", significando maior coerência com os princípios e diretrizes do SUS (BRIZOLA, 2010). 
Assim, de acordo com o Cadastro Nacional de Estabelecimentos de Saúde do Brasil, desde 2004, 202 unidades hospitalares aderiram ao Programa Interministerial de Certificação dos Ministérios da Saúde e da Educação (BRASIL, 2019)

Portanto, ao compreender a imprescindibilidade da contratualização dos Hospitais de Ensino para a reafirmação da rede de saúde do SUS, nos aspectos da formação de profissionais, da pesquisa para o setor e da atenção à saúde qualificada e resolutiva dentro da rede de cuidados progressivos à saúde, e por se tratar de um tema novo, ainda pouco explorado, este estudo teve como objetivo avaliar, na perspectiva dos stakeholders, o desempenho de um Hospital de Ensino do Estado do Ceará após a sua contratualização com o Sistema Único de Saúde como Hospital de Ensino, nos eixos "Açôes estratégicas na área da assistência", "Gestão, Ensino e Pesquisa" e "Modelo de Alocação de Recursos Financeiros", analisando e comparando as reivindicaçôes, as preocupações e as questôes levantadas pelos stakeholders relativas a cada um desses três eixos.

\section{Método}

Tratou-se de uma pesquisa avaliativa, descritiva e exploratória, de abordagem qualitativa, realizada em um Hospital de Ensino do Estado do Ceará, no período de novembro de 2014 a maio de 2015. Esta pesquisa faz parte da dissertação de mestrado "Avaliação responsiva e construtivista de um Hospital de Ensino do Estado do Ceará" aprovada pelo Comitê de Ética em Pesquisa envolvendo Seres Humanos sob CAAE 37096214.9.0000.5053.

Conforme Contandriopoulos et al. (1997, p. 37) a pesquisa avaliativa é "o procedimento que consiste em fazer um julgamento ex-post de uma intervenção com base em métodos científicos". Este tipo de pesquisa analisa a pertinência, os fundamentos técnicos, a produtividade, os efeitos e o rendimento de uma intervenção, assim como as relaçôes existentes entre a intervenção e o contexto no qual ela se situa.

Para a realização deste estudo, utilizou-se o modelo de Avaliação de Quarta Geração de Guba e Lincoln (1989), o qual é caracterizado por corresponder a uma avaliação inclusiva e participativa, que é feita como um processo de negociação entre os atores envolvidos na intervenção a ser avaliada, tendo como núcleo operacional o círculo hermenêutico dialético (Figura 1). 


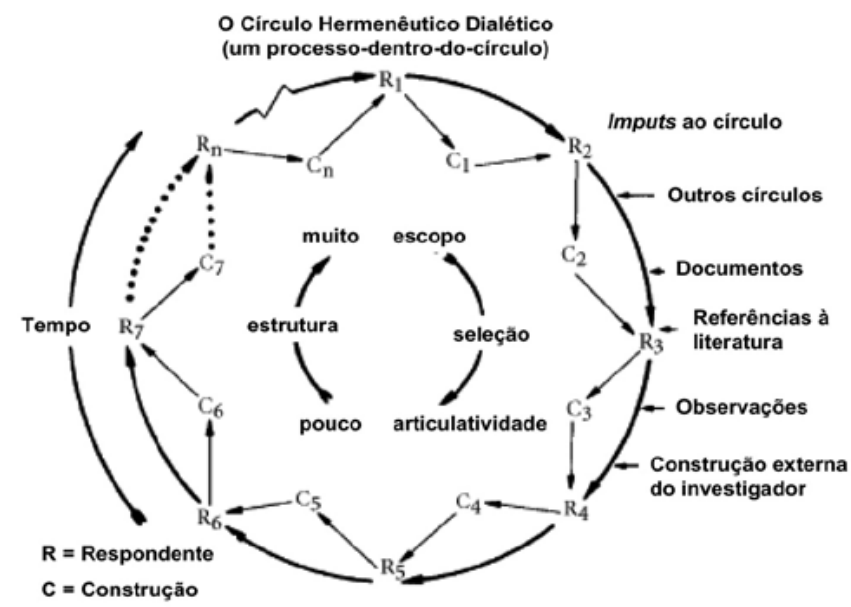

Fonte: Guba e Lincoln (1989)

Cabe salutar que os círculos hermenêuticos dialéticos integram o fluxo de doze etapas da metodologia da Avaliação de Quarta Geraçáo, tal como determinadas por Guba e Lincoln (Quadro 1). Porém, para fins deste estudo foram seguidos os sete primeiros passos dos 12 propostos pelo círculo hermenêutico dialético de Guba e Lincoln (1989), em virtude da adequação do tempo da pesquisa. Não foram incluídas, no estudo, as etapas preparação de uma agenda de negociaçáo, coleta e sofisticaçáo da informação, condução da negociação, compilação do relatório e reciclagem.

\begin{tabular}{|ll|}
\hline PASSO & AÇÓES \\
\hline 1. Contratualização & Iniciar contrato com cliente \\
\hline 2. Organizaçáo & $\begin{array}{l}\text { Selecionar e treinar a equipe de avaliação; fazer arranjos para } \\
\text { a entrada em campo; fazer arranjos logísticos e acessar fatores } \\
\text { políticos locais }\end{array}$ \\
\hline $\begin{array}{l}\text { 3. Identificação dos implicados no } \\
\text { programa avaliado (stakeholders) }\end{array}$ & $\begin{array}{l}\text { Identificar os implicados no programa (stakeholders); montar } \\
\text { estratégias de pesquisa contínuas; obter e formalizar condiçóes de } \\
\text { concordância em participar da pesquisa (submetendo o protocolo } \\
\text { a um comitê de ética em pesquisa) }\end{array}$ \\
\hline $\begin{array}{l}\text { 4. Desenvolvimento de } \\
\text { construçóes conjuntas dentro de } \\
\text { grupos }\end{array}$ & $\begin{array}{l}\text { "Rodar" os círculos hermenêuticos dialéticos para fazer emergir } \\
\text { as construçóes conjuntas; checar credibilidade }\end{array}$ \\
\hline
\end{tabular}




\begin{tabular}{|c|c|}
\hline PASSO & AÇÓES \\
\hline $\begin{array}{l}\text { 5. Alargamento das construçóes } \\
\text { conjuntas dos implicados no } \\
\text { programa (stakeholders) através de } \\
\text { novas informaçôes e do aumento } \\
\text { da sofisticação }\end{array}$ & $\begin{array}{l}\text { Refazer os círculos hermenêuticos dialéticos, utilizando } \\
\text { informação documental, interpolação de entrevistas de } \\
\text { esclarecimento e de observaçôes, referências bibliográficas e a } \\
\text { construção externa (ética) dos investigadores }\end{array}$ \\
\hline $\begin{array}{l}\text { 6. Classificação das reivindicações, } \\
\text { preocupaçôes e questôes } \\
\text { solucionadas por consenso }\end{array}$ & $\begin{array}{l}\text { Identificar as reivindicaçôes, preocupaçóes e questóes } \\
\text { solucionadas por consenso; deixar de lado como componentes de } \\
\text { relatórios de casos }\end{array}$ \\
\hline $\begin{array}{l}\text { 7. Priorização dos itens não } \\
\text { solucionados por consenso }\end{array}$ & $\begin{array}{l}\text { Determinar processo de priorização participativo; submeter itens } \\
\text { para priorizaçáo; checar credibilidade }\end{array}$ \\
\hline $\begin{array}{l}\text { 8. Coleta e sofisticação da } \\
\text { informação }\end{array}$ & $\begin{array}{l}\text { Coletar informação e treinar negociadores no seu uso através de: } \\
\text { utilização de novos círculos hermenêuticos dialéticos, obtenção } \\
\text { de informação existente, utilização de novos instrumentos ou de } \\
\text { instrumentos existentes, e realização de novos estudos }\end{array}$ \\
\hline $\begin{array}{l}\text { 9. Preparação da agenda para a } \\
\text { negociação }\end{array}$ & $\begin{array}{l}\text { Definir e elucidar itens não solucionados; elucidar construçôes } \\
\text { que competem entre si; iluminar, dar apoio a e refutar itens; } \\
\text { prover sofisticação no treinamento; testar agenda }\end{array}$ \\
\hline 10. Condução da negociação & $\begin{array}{l}\text { Selecionar círculo hermenêutico dialético representativo; "rodar" } \\
\text { o círculo; moldar a construção conjunta; checar credibilidade; } \\
\text { determinar a ação }\end{array}$ \\
\hline 11. Compilação do relatório & $\begin{array}{l}\text { Compilar relatórios dos grupos de envolvidos no programa } \\
\text { (stakeholders); compilar o relatório do caso }\end{array}$ \\
\hline 12. Retomada & Retomar todo o processo \\
\hline
\end{tabular}

Fonte: Guba e Lincoln (1989)

Para a realização da pesquisa, foram realizados contatos telefônicos e visitas locais ao hospital pesquisado a fim de esclarecer à gestão hospitalar os objetivos do estudo e obter autorização para desenvolvê-lo mediante a assinatura da Carta de Anuência e do Termo de Fiel Depositário pelos gestores hospitalares e suas secretarias contratuantes. Posteriormente, definiu-se uma agenda para a coleta dos dados e identificaram-se espaços físicos disponíveis e adequados para a realização das entrevistas, pela conveniência dos participantes.

Desta maneira, participaram da pesquisa os grupos de interesse do processo de avaliação de um hospital de ensino, conforme as três classes abrangentes definidas por Guba e Lincoln (1989, p. 49): 
1) os representantes, envolvidos na produção, utilização e implementação do objeto de avaliação, que compreenderam os gestores do hospital de ensino, das IES, da secretaria contratuante e da Comissão de Acompanhamento do Contrato;

2) os beneficiários, que compreendem as "pessoas que de alguma maneira tiram proveito do uso do objeto da avaliaçâo", podendo ser representados pelos internos de medicina e enfermagem e residentes em saúde, profissionais; e,

3) as vítimas, que são "as pessoas afetadas negativamente pelo uso do objeto da avaliação", representados pelos docentes, preceptores e profissionais.

Assim, os 33 participantes da pesquisa foram agrupados em 5 círculos hermenêutico-dialéticos (Tabela 1), os quais avaliaram o desempenho do hospital pesquisado quanto aos eixos dos hospitais de ensino dispostos pelo Programa de Reestruturação dos Hospitais de Ensino: "Açóes estratégicas na área da assistência", "Gestão, Ensino e Pesquisa" e "Modelo de Alocação de Recursos Financeiros".

\begin{tabular}{|c|c|c|c|c|c|c|c|c|c|}
\hline \multicolumn{10}{|c|}{ STAKEHOLDERS DA AVALIAÇÃO DE HE } \\
\hline \multicolumn{2}{|c|}{$\begin{array}{l}\text { Stakeholders da } \\
\text { Gestão do SUS, } \\
\text { HE, Escolas } \\
\text { Médicas }\end{array}$} & \multicolumn{2}{|c|}{$\begin{array}{c}\text { Stakeholders da } \\
\text { Gestão: Comissão de } \\
\text { Acompanhamento do HE }\end{array}$} & \multicolumn{2}{|c|}{$\begin{array}{c}\text { Stakeholders da } \\
\text { Assistência }\end{array}$} & \multicolumn{2}{|c|}{$\begin{array}{c}\text { Stakeholders do } \\
\text { Ensino e Pesquisa: } \\
\text { Docentes e } \\
\text { Preceptores }\end{array}$} & \multicolumn{2}{|c|}{$\begin{array}{c}\text { Stakeholders do } \\
\text { Ensino e Pesquisa: } \\
\text { Internos e } \\
\text { Residentes }\end{array}$} \\
\hline Descrição & $\mathrm{N}$ & Descrição & $\mathrm{N}$ & Descrição & $\mathrm{N}$ & Descrição & $\mathrm{N}$ & Descrição & $\mathrm{N}$ \\
\hline $\begin{array}{l}\text { Gestão local } \\
\text { do SUS }\end{array}$ & 01 & $\begin{array}{l}\text { Representação } \\
\text { da Secretaria de } \\
\text { Saúde }\end{array}$ & 02 & $\begin{array}{l}\text { Direção } \\
\text { Clínica e de } \\
\text { Enfermagem }\end{array}$ & 02 & $\begin{array}{l}\text { Coordenação } \\
\text { Residências }\end{array}$ & 02 & Residentes & 05 \\
\hline Gestão do HE & 02 & $\begin{array}{l}\text { Representação } \\
\text { Docente das IES }\end{array}$ & 02 & $\begin{array}{l}\text { Coordenação } \\
\text { Clínica } \\
\text { Médica }\end{array}$ & 01 & $\begin{array}{l}\text { Preceptores } \\
\text { das } \\
\text { Residências }\end{array}$ & 05 & $\begin{array}{l}\text { Internos de } \\
\text { Medicina }\end{array}$ & 01 \\
\hline \multirow[t]{3}{*}{$\begin{array}{l}\text { Coordenação } \\
\text { das Escolas } \\
\text { Médicas e de } \\
\text { Enfermagem }\end{array}$} & 02 & $\begin{array}{l}\text { Representação } \\
\text { Discente das IES }\end{array}$ & 02 & $\begin{array}{l}\text { Coordenação } \\
\text { Cirurgia } \\
\text { Geral }\end{array}$ & 01 & $\begin{array}{l}\text { Coordenação } \\
\text { Internato de } \\
\text { Medicina e } \\
\text { Enfermagem }\end{array}$ & 02 & & \\
\hline & & $\begin{array}{l}\text { Representação } \\
\text { do Conselho } \\
\text { Municipal de } \\
\text { Saúde }\end{array}$ & 01 & $\begin{array}{l}\text { Coordenação } \\
\text { Pediatria }\end{array}$ & 01 & & & & \\
\hline & & & & $\begin{array}{l}\text { Coordenação } \\
\text { Ginecologia } \\
\text { e Obstetrícia }\end{array}$ & 01 & & & & \\
\hline Total & 05 & & 07 & & 06 & & 09 & & 06 \\
\hline
\end{tabular}

Fonte: própria 
Para a operacionalização dos círculos hermenêutico-dialéticos, foram realizadas entrevistas abertas com cada respondente, considerando o fluxo do processo de construçôes conjuntas a partir da técnica de comparação constante proposta pela Teoria Fundamentada de Glaser e Strauss (1969).

Com isso, ao primeiro respondente de cada círculo hermenêutico-dialético, selecionado pela posição privilegiada no contexto de investigação em estudo, foi aplicada uma entrevista aberta e, aos demais respondentes, selecionados de acordo com a posição que desempenhavam no contexto do estudo, foram aplicadas entrevistas semi-estruturadas a partir das construçôes anteriores. Assim, o processo foi repetido com a integração de novos respondentes ao círculo até a informação coletada se tornar redundante ou houvesse duas ou mais construçóes sobre ela que permanecessem em conflito.

Durante o processo de desenvolvimento das construçóes conjuntas, utilizouse da observação participante e da análise dos relatórios dos anos 2013 e 2014 da Comissão de Acompanhamento das Metas do Hospital de Ensino para alargamento dessas construçôes. Isto é, as informaçôes resultantes da análise documental e observação foram expostas durante a entrevista semi-estruturada para favorecer a construção dos respondentes sobre elas.

Para fins de análise e organização dos resultados, as construçôes conjuntas consensuadas entre os respondentes foram classificadas em códigos focais, resultantes da aplicação da técnica de comparação constantes, e agrupadas nos organizadores da Avaliação de Quarta Geração (reivindicaçôes, preocupaçôes e questôes) para cada eixo normativo do Programa de Restruturação dos Hospitais de Ensino.

Para fins desse estudo, considerou-se como reivindicação as alegações favoráveis ao processo de desempenho do hospital de ensino, preocupação as afirmaçóes que os interessados apresentassem como desfavoráveis ao desempenho desse hospital e questôes como qualquer situação no qual os agentes pudessem discordar.

Portanto, considerando que as questóes se configuram em alegaçóes não consensuadas entre os atores envolvidos na avaliaçáo e que, de acordo com o método proposto, devem ser organizadas e apresentadas aos respondentes em uma agenda de negociação (Passos 7, 8, 9 e 10), neste artigo serão apresentadas as reivindicaçôes e as preocupaçôes consensuadas entre os respondentes e as questóes que emergiram do processo avaliativo. 


\section{Resultados}

O processo avaliativo responsivo e construtivista em um hospital de ensino permitiu verificar a existência de preocupaçóes e questôes relacionadas ao eixo normativo Eixo Ações Estratégicas na Área da Assistência do Programa de Reestruturação dos Hospitais de Ensino no âmbito do SUS, bem como a existência de reivindicaçóes e preocupações no eixo Gestão, Ensino e Pesquisa e de reivindicaçôes no eixo Modelo de Alocação de Recursos Financeiros (Quadro 2).

\begin{tabular}{|c|c|c|c|}
\hline \multirow{2}{*}{$\begin{array}{c}\text { Eixos normativos } \\
\text { do Programa de } \\
\text { Reestruturaçáo de } \\
\text { Hospitais de Ensino }\end{array}$} & \multicolumn{3}{|c|}{$\begin{array}{c}\text { Organizadores da Avaliação de Quarta Geraçáo } \\
\text { (Guba e Lincoln, 1989) }\end{array}$} \\
\hline & Reivindicações & Preocupaçóes & Questôes \\
\hline $\begin{array}{l}\text { Ações Estratégicas na } \\
\text { Área da Assistência }\end{array}$ & & $\begin{array}{l}\text { - O Hospital de Ensino } \\
\text { impacta e é impactado } \\
\text { pela Rede de Atenção à } \\
\text { Saúde }\end{array}$ & $\begin{array}{l}\text { - Houve melhoria na } \\
\text { assistência à saúde } \\
\text { hospitalar } \\
\text { - Houve melhoria nas } \\
\text { políticas prioritárias no } \\
\text { âmbito hospitalar }\end{array}$ \\
\hline $\begin{array}{l}\text { Gestão, Ensino e } \\
\text { Pesquisa }\end{array}$ & $\begin{array}{l}\text { - As parcerias entre } \\
\text { Hospital de Ensino e } \\
\text { Instituiçóes de Ensino } \\
\text { Superior são relevantes } \\
\text { - É imprescindível a } \\
\text { atuação da Comissão } \\
\text { de Avaliação e } \\
\text { Monitoramento das } \\
\text { Metas do Hospital }\end{array}$ & $\begin{array}{l}\text { - Há diferenciação no } \\
\text { custo da assistência em } \\
\text { Hospital de Ensino } \\
\text { - Não há planos de } \\
\text { cargos e carreiras no } \\
\text { hospital } \\
\text { - A preceptoria no } \\
\text { hospital é um desafio } \\
\text { - As pesquisas ainda são } \\
\text { insuficientes }\end{array}$ & \\
\hline $\begin{array}{l}\text { Modelo de Alocaçáo } \\
\text { de Recursos } \\
\text { Financeiros }\end{array}$ & $\begin{array}{l}\text { - Financiamento } \\
\text { específico à } \\
\text { contratualizaçáo como } \\
\text { Hospital de Ensino }\end{array}$ & & \\
\hline
\end{tabular}

A utilização dos círculos hermenêutico-dialéticos sobre a avaliação de desempenho obtida pelo hospital, no Eixo Ações Estratégicas na Área da Assistência, favoreceu a apreensão de preocupaçóes e questôes e ausências de reivindicaçóes no referido eixo.

No tocante às preocupaçóes relacionadas ao desempenho do hospital após a contratualização como HE, foi possível evidenciar, a partir das alegaçôes dos 
stakeholders, a construção conjunta "O Hospital de Ensino impacta e é impactado pela Rede de Atenção à Saúde".

Neste contexto, embora o hospital em estudo venha cumprindo suas funçôes frente à contratualização, a inserção dele na rede de atenção à saúde emerge como uma preocupaçáo dos stakeholders da gestáo e do ensino, visto que a forma de organização da rede e o funcionamento do sistema de referência favorecem para a superlotação do hospital, e, consequentemente, para um desempenho diminuto na atenção à saúde e nas políticas prioritárias.

Conforme as construções dos atores, a contribuição do Hospital de Ensino para a rede de atenção está relacionada à interiorização de profissionais da saúde no Estado do Ceará, tendo em vista os egressos desse estabelecimento de saúde se fixarem profissionalmente na regiáo do hospital pesquisado.

No que concerne às alegaçóes sobre o desempenho do hospital de ensino no eixo Açôes Estratégicas nas Áreas Assistenciais, pode-se verificar divergências de opiniōes entre os stakeholders da gestão, da assistência e do ensino e pesquisa quanto à melhoria na assistência e nas políticas prioritárias. Fato que favoreceu o surgimento das questôes "Houve melhoria na assistência à saúde hospitalar" e "Houve melhoria nas políticas prioritárias no âmbito hospitalar”.

Os stakeholders da gestão do SUS, das Escolas Médicas e do HE apontaram que a certificação como HE contribuiu para o desempenho do hospital nessa área, interferindo na melhoria dos processos assistenciais, indicadores de saúde e investimentos, além do avanço da atuação multidisciplinar na unidade em estudo. Construçôes essas que obtiveram a concordância dos stakeholders da assistência e do ensino e pesquisa, tendo em vista eles corroborarem que a contratualização favoreceu a qualificação da assistência, mediante a inserção de estudantes, internos, residentes e preceptores nos serviços hospitalares, além da adequação do dimensionamento de profissionais e a melhoria em estrutura e equipamentos.

Para os representantes da comissão de acompanhamento do hospital de ensino, a melhoria da assistência foi impulsionada pela pesquisa de satisfação dos usuários, pela atuação das comissões intra-hospitalares, tendo os docentes e discentes como revitalizadores e instigadores de reflexão e mudança das práticas em saúde. Aspectos esses que, conforme as construçóes dos stakeholders da comissão de acompanhamento, contribuíram para a melhoria significativa da atenção nos serviços 
de pediatria e clínica médica, para atuação multidisciplinar e, consequentemente, melhor avaliação do paciente.

Todavia, houve divergência na compreensão da melhoria significativa da assistência, uma vez que os stakeholders da gestão, da assistência e ensino e pesquisa reiteraram a superlotação nos serviços do hospital e a demanda excessiva de pacientes que necessitam de atendimento, apresentam aspectos limitantes para a melhoria significativa da assistência à saúde.

Durante o processo avaliativo, foi percebido que a maioria dos stakeholders apresentou dificuldade de desenvolver construçôes sobre o desempenho do hospital de ensino nas políticas prioritárias do SUS, devido ao desconhecimento de como essas políticas são operacionalizadas no contexto hospitalar, sendo considerada pelos atores como uma preocupação para o desempenho da unidade em estudo.

A avaliação do eixo normativo Gestão, Ensino e Pesquisa permitiu depreender a existência de reivindicaçóes quanto: "As parcerias entre Hospital de Ensino e Instituições de Ensino Superior são relevantes" e "É imprescindível a atuação da Comissão de Avaliação e Monitoramento das Metas do Hospital”.

Os representantes da gestão, assistência, e ensino e pesquisa foram convergentes quanto à compreensão da importância da parceria entre o Hospital e as Instituiçôes de Ensino Superior (IES) para a contratualização como HE e o desempenho hospitalar. De acordo com os participantes, a proximidade e o diálogo que há entre hospital e as IES favoreceu a melhoria do hospital nos eixos normativos propostos no Programa de Reestruturação dos Hospitais de Ensino.

Assim, foi apontado que a contratualização organizou e estabeleceu as funçóes do hospital frente às instituiçóes formadoras e o SUS, permitindo a ampliação e criação de programas de residência médica, o amadurecimento da pesquisa no âmbito hospitalar e a permanência de profissionais na regiáo de saúde.

Para esses atores, a Comissão de Acompanhamento de Contratos é uma ferramenta importantíssima ao processo de contratualização do hospital com o SUS, visto que possui como função avaliar mensalmente o cumprimento das metas qualitativas pactuadas nas áreas assistência, gestão e ensino e pesquisa e a alocação adequada do incentivo financeiro advindo da certificação como Hospital de Ensino nos referidos eixos.

Entretanto, afirmaram ainda que a comissão apresenta fragilidades quanto ao papel no processo da contratualização do hospital e que a avaliação das metas pactuadas 
no plano operativo por essa comissão sofre o viés do instrumento de avaliação, sendo indicadas a necessidade de maior autonomia dessa comissão e a atuação in loco.

Cabe salutar que neste aspecto não houveram construçóes emergentes dos residentes e internos inseridos no hospital, demonstrando o desconhecimento desses atores quanto ao programa de certificação dos hospitais de ensino e contribuição desse para o processo formativo em saúde.

No que se refere às alegações desfavoráveis ao desempenho do hospital após a contratualização no eixo Gestão, Ensino e Pesquisa, emergiram as preocupações: "Há diferenciação no custo da assistência em Hospital de Ensino"; "Não há planos de cargos e carreiras no hospital"; "A preceptoria no hospital é um desafio" e "As pesquisas ainda são insuficientes".

No que concerne à "Há diferenciação no custo da assistência em Hospital de Ensino", os discursos dos participantes demonstraram que a inserção de residentes e internos na assistência eleva o custo do hospital, devido ao maior percentual de exames solicitados para definiçáo de diagnóstico, favorecendo prolongamento do tempo de internação e aumento das despesas com equipamentos e material médicohospitalares, alimentação, rouparia e equipamentos de proteção individual.

Contudo, ao passo que reconhecem o aumento do custo da assistência com a inserção do ensino no hospital, os stakeholders da gestão, da assistência e do ensino e pesquisa, ressaltam que a qualificação da assistência proporcionada pela inserção de residentes e internos no hospital justifica e supera os custos onerados.

Quanto à "Não há planos de cargos e carreiras no hospital", os stakeholders da assistência e do ensino e pesquisa entram em consenso que a ausência de planos de cargos e carreiras fomenta desmotivação nos profissionais e dificuldade de envolvimento do corpo clínico nas atividades de ensino-assistência. Porém, salientaram a existência de tentativas por parte da gestão de se instituir um plano de cargos, carreiras e salários no hospital.

Apontaram também a preceptoria como uma preocupação para o desempenho do hospital de ensino, visto que, de acordo com o relato deles, a preceptoria acontece de forma diferenciada nos serviços do hospital, entre os cursos da saúde e entre as modalidades de formaçáo (residência e internato), inexistindo atividades de capacitação para esses profissionais.

Neste contexto, os stakeholders da gestão e da assistência afirmaram que a dificuldade no desenvolvimento da preceptoria no hospital se dá devido aos 
profissionais ainda náo depreenderem o papel do hospital como unidade de ensino e desconhecerem os conceitos e fundamentaçáo teórica sobre preceptoria na saúde. Corroboraram, ainda, que a atividade de preceptoria é desempenhada com êxito em alguns serviços do hospital e que as competências dessa função diferem entre os serviços, havendo, portanto, a necessidade de elaboração e monitoramento de um plano de trabalho para esses profissionais, além da ampliação do quantitativo de preceptores no serviço e maior proximidade entre esses e os residentes.

Entretanto, para os stakeholders do ensino e pesquisa (docentes e preceptores) a contratualização como hospital de ensino fomentou melhorias no desenvolvimento da preceptoria no hospital, já que possibilitou a ampliação do quantitativo de profissionais para desempenharem essa atividade, bem como incentivo financeiro para eles. Porém, reconheceram a necessidade de acompanhamento, gerenciamento e capacitação para a preceptoria no hospital.

Concernente ao desenvolvimento de pesquisas no hospital, os stakeholders da gestão, da assistência e do ensino e pesquisa apontaram preocupação quanto a insuficiência dessa prática na unidade hospitalar. Para eles, embora o hospital disponibilize incentivo financeiro para o desenvolvimento de pesquisas, por meio de editais de seleção, essa ação não provoca impactos significativos no desenvolvimento de diretrizes e tecnologias para o cuidado em saúde no referido hospital.

A avaliaçáo do eixo normativo Modelo de Alocaçâo de Recursos Financeiros favoreceu a apreensão de reivindicaçóes quanto a possibilidade de "Financiamento específico à contratualização como Hospital de Ensino".

Para os stakeholders da Gestão do SUS, Hospital de Ensino e Escolas Médicas, da Comissão de Acompanhamento das Metas do Hospital de Ensino, da Assistência, e do Ensino e Pesquisa (Docentes e Preceptores) a contratualizaçáo com o SUS, como Hospital de Ensino, favoreceu o repasse mensal de recurso financeiro, adicional ao valor pré-fixado contratualizado.

De acordo com os atores da avaliação, o financiamento específico para unidades hospitalares de ensino é imprescindível para o desempenho da gestão nessas unidades, tendo em vista permitir a organização das áreas do ensino e pesquisa, por meio da adequação da estrutura física, do apoio para a formação, como manutenção de preceptoria e para a pesquisa na saúde, configurando-se suporte financeiro para a manutenção das ações de gestão, assistência, e ensino e pesquisa nesses. 
Entretanto, a partir das construçóes conjuntas, foi possível verificar ainda que se faz necessário um alinhamento financeiro das ações de ensino e pesquisa e assistência no hospital para que haja um melhor desempenho na gestão, sendo importante considerar que os stakeholders representantes dos internos e residentes não apresentaram alegaçōes referentes ao repasse financeiro específico à contratualização, corroborando a não participação e desconhecimento desses atores acerca do financiamento dessas unidades hospitalares.

\section{Discussão}

O Programa de Reestruturação dos Hospitais de Ensino e dos Hospitais Filantrópicos surgiu no ano de 2004 com o objetivo de reorientar e reformular a política para essas unidades hospitalares, de forma a qualificar a atenção à saúde prestada por essas instituiçôes do SUS, uma vez que são compreendidos como uma "estratégia de formar pessoas, de prestar serviços à atenção à saúde de alta qualidade e, mais do que referência, de ser ponto de atenção na rede do SUS” (BRASIL, 2010).

Conquanto, os resultados desse estudo demonstraram a ausência de mudanças significativas no eixo assistência do hospital em estudo, bem como apresentaram a relação entre o HE e a Rede de Atenção à Saúde como uma preocupação devido a organização do SUS e a oferta da assistência à saúde mediante rede descentralizada de serviços de saúde.

Para Barata, Mendes e Bittar (2010) na lógica da atenção à saúde no SUS, as doenças mais comuns e as crônicas devem ser atendidas nas unidades básicas de saúde e os atendimentos especializados devem ser encaminhados para serviços mais complexos, de caráter secundário e terciário, como os HE. Entretanto, apontam que nessas unidades hospitalares ainda é realizada grande proporção de atendimentos de média e baixa complexidade, favorecendo o bloqueio das agendas de procedimentos de maior complexidade, surgimento de filas de espera e demanda reprimida, aspectos esses que vão ao encontro dos achados desta pesquisa.

Estudo realizado com quatro hospitais de universitários e suas secretarias contratuantes, demonstrou que, frequentemente, cabe aos hospitais universitários o desempenho de atribuiçóes que fogem da sua vocação mais primordial de prover assistência especializada, num cenário de formação de profissionais de saúde, devido para muitos da população brasileira a porta de entrada do sistema de saúde continuar sendo os serviços de emergência (MACHADO e KUCHENBECKER, 2007). 
Neste contexto, pode-se afirmar que ainda se faz necessária maior integração entre os $\mathrm{HE}$ e a rede de cuidados locais de saúde, a fim de conter o desperdício de recursos, experimentar novas formas de gerenciamento em saúde e adequar o ensino às necessidades de formação de profissionais conforme à demanda social e epidemiológica da população do entorno (LOBO et al, 2010).

No contexto das reivindicações ao eixo normativo Gestão, Ensino e Pesquisa, a parceria entre HE e IES é considerada condição essencial para a certificação como Hospital de Ensino, visto que para serem certificados devem abrigar, formalmente e em caráter permanente e contínuo, estudantes de um curso de medicina e de pelo menos dois outros cursos de graduação na área da saúde, além de programas de Residência Médica, regularmente credenciados pela Comissão Nacional de Residência Médica (BRASIL, 2004b).

Portanto, uma vez certificados, os HE firmam contrato com o gestor do SUS por meio da definição e pactuação de metas quantitativas e qualitativas a serem realizadas pelos hospitais, dando materialidade ao processo de acompanhamento e avaliação sistemática realizados pela Comissão de Acompanhamento do Contrato (LOBO et al, 2009), as quais têm como atribuiçóes acompanhar o indicativo do alcance das metas, apontando providências e redirecionamentos (BRASIL, 2012).

Não obstante; ao serem consideradas instituiçôes caras, uma vez que contemplam atendimentos de alta complexidade e atividades que mesclam assistência médica com procedimentos didáticos (DALLORA e FOSTER, 2008), Lobo et al (2009) apontam a necessidade de diferenciação do valor repassado pelos procedimentos realizados nos HE.

Estudos realizados em hospitais de ensino na Espanha apontam que a quantidade de residentes pode impactar 9\% a mais no custo estimado dos $\mathrm{HE}$ em relação aos hospitais sem ensino, sendo na Europa e Estados Unidos o custo ser de até $25 \%$ a mais que nos demais hospitais gerais (BITTAR e MAGALHÁES, 2008). Na Austrália, estudos demonstram que o custo dos Hospitais Universitários é de 12\% maior do que em hospitais não universitários e na Coréia do Sul este percentual sobe para 28\% quando comparados a hospitais de mesma complexidade (BRASIL, 2012).

No entanto, em estudo sobre o impacto da reforma de financiamento em hospitais de ensino no Brasil, a diferenciação de custos em HE é corroborada ao ser afirmado que, apesar das atividades de ensino estarem associadas ao aumento do custo da produção assistencial nos hospitais, o desenvolvimento e a excelência do 
ensino e pesquisa nesses hospitais podem ser considerados estratégia prioritária para o enfrentamento da crise de financiamento desses hospitais (LOBO et al, 2009).

No que tange ao plano de cargos e carreiras nos HE, a avaliação periódica dos profissionais, com técnicas atuais e a participação nos resultados servem de estímulo para o crescimento profissional e maior retorno produtivo e financeiro às unidades (LOBO et al, 2009), aspectos esses que emergiram como preocupaçóes entre stakeholders do círculo hermenêutico ensino e pesquisa.

No contexto da preceptoria em HE, a Portaria Interministerial no 2400 de 2007, que estabelece requisitos para a certificação de unidades hospitalares como Hospital de Ensino, explicita no artigo $7^{\circ}$ que esses hospitais deverão "garantir acompanhamento diário por docente ou preceptor para os estudantes de graduação e para os residentes" (BRASIL, 2007). Aspecto também ratificado na portaria no 285 de 2015, uma vez que de acordo com esta o acompanhamento diário por docente ou preceptor deve seguir a distribuição de um preceptor com carga horária de 20 horas semanais para cada três residentes ou um preceptor com carga horária de 40 horas semanais para cada 06 residentes, e um preceptor para cada 12 alunos de internato (BRASIL, 2015).

Em relação ao desenvolvimento de pesquisas nessas unidades hospitalares, os hospitais de ensino devem dispor de projeto institucional próprio ou da IES à qual forem vinculados para o desenvolvimento de atividades regulares de pesquisa científica e de mecanismos de gerenciamento das atividades de ensino e pesquisa desenvolvidas no hospital (BRASIL, 2007).

No âmbito do modelo de alocação de recursos dos HE, o incentivo/financiamento específico à contratualização como Hospital de Ensino emergiu neste estudo como uma reivindicação ao desempenho da unidade hospitalar. Aspecto corroborado por estudo realizado em Hospitais Universitários Federais, quando se verificou que o aumento dos recursos implicou em maior desempenho da unidade hospitalar (LOBO et al, 2009).

Desta forma, a Portaria Interministerial no 1.702 afirma que uma vez certificado como hospital de ensino, a instituição hospitalar deverá firmar convênio com o gestor local de saúde, no qual deve estar explicito o novo modelo de financiamento e alocação de recursos financeiros para a atenção à saúde, gestão, ensino e educação de pesquisa por meio da orçamentação mista do custeio do hospital de ensino (BRASIL, 2004a). 


\section{Consideraçóes Finais}

A avaliação responsiva e construtivista aplicada nesta pesquisa sobre o desempenho de um hospital de ensino após a contratualização com o SUS, permitiu depreender que o Programa de Reestruturaçáo dos Hospitais de Ensino no Brasil favoreceu, ao hospital pesquisado, mudanças relativas aos três eixos normativos dos hospitais de ensino, com melhorias nos eixos normativos "Gestão, Ensino e Pesquisa" e "Modelo de Alocação de Recursos Financeiros". Contudo, como todo processo de remodelagem, emergiram também preocupaçóes e questôes nos eixos normativos Ações Estratégicas na Área da Assistência e Gestão, Ensino e Pesquisa.

As preocupaçóes emergentes durante o processo avaliativo evidenciaram que se faz necessária uma agenda, com participação de gestores e demais atores do hospital de ensino, com a finalidade de definir metas e planos de ação para o sucesso da política nos eixos normativos "Açôes Estratégicas na Área da Assistência" e "Gestão, Ensino e Pesquisa". Todavia, considerando que o tempo para condução da pesquisa foi fator limitante para a negociação das questōes apresentadas pelos stakeholders no eixo "Ações Estratégicas na Área da Assistência”, não foi possível o consenso entre os participantes da avaliação no que concerne ao impacto do Programa de Reestruturação dos Hospitais de Ensino na melhoria da assistência hospitalar e na participação do hospital pesquisado nas políticas prioritárias do SUS.

Nesse contexto, a adoção do modelo construtivista e responsivo para a apreensão dos efeitos da contratualização em hospitais de ensino emerge como uma possibilidade avaliativa, favorecendo o reconhecimento de aspectos favoráveis, desfavoráveis e conflituosos do programa e a reorientação das práticas de gestão, assistência, ensino e pesquisa nessas unidades hospitalares.

Diante disso, novas investigações sobre a temática abordada são necessárias a fim de aprimorar o modelo avaliativo utilizado nesta pesquisa e de responder questôes emergentes relacionadas ao desempenho dos hospitais de ensino após a contratualização com o SUS e ao impacto do Programa de Reestruturação dos Hospitais de Ensino na conformação normativa e funcional destes e nos indicadores da Rede de Atenção à Saúde. 


\section{Referências}

BARATA, L. R. B; MENDES, J. D. V.; BITTAR, O. J. N. V. Hospitais de ensino e o Sistema Único de Saúde. RAS., v. 12, n. 46, 2010. Disponível em: <http://sistema4.saude.sp.gov.br/sahe/ documento/ras46.pdf>. Acesso em: 25 jun. 2013.

BITTAR, O. J. N. V. Indicadores de qualidade e quantidade em saúde - parte II. Revista de Administração em Saúde. São Paulo, v. 6, n. 22, p.15-18, jan./mar. 2004.

BITTAR, O. J. N. V.; MAGALHÃES, A. Hospitais de ensino: informações para monitoramento. $R A S$., v. 10, n. 38, 2008. Disponível em: <http://sistema.saude.sp.gov.br/sahe/documento/ras38. pdf>. Acesso em: 25 jun. 2013.

BRASIL. Constituição (1988). Constituição da República Federativa do Brasil. Brasília: Senado, 1988.

BRASIL, Ministério da Educação e da Saúde. Portaria Interministerial 1.000 de 15 de abril de 2004. Brasília: Ministério da Saúde; 2004a. Disponível em: <http://www. femerj.org.br/Boletim/Federal/Ministerio\%20Saude/GM/2004/Junho/PORTARIA\%20 INTERMINISTERIAL\%20N\%BA\%201000.pdf>. Acesso em: 10 out 2011.

- Portaria Interministerial 1.702/MEC/MS de 17 de agosto de 2004. Brasília: Ministério da Saúde; 2004b. Disponível em: <http://bvsms.saude.gov.br/bvs/saudelegis/gm/2004/ prt1702_17_08_2004.html>. Acesso em: 19 mar. 2020.

. Portaria Interministerial no 2.400 de 02 de outubro de 2007. Estabelece os requisitos para a certificação de unidades hospitalares como Hospital de Ensino. Disponível em: <http://www.saude.mt.gov.br/upload/legislacao/2400-\%5B2830-120110-SES-MT\%5D. pdf>. Acesso em: 10 out. 2011.

Secretaria de Atenção à Saúde. Departamento de Atenção Especializada. Análise do Processo de Contratualização dos Hospitais de Ensino e Filantrópicos no SUS: dificuldades, perspectivas e propostas. Brasília (DF): 2010.

- Sociedade Hospital Samaritano. Política de Reestruturação dos Hospitais de Ensino e Filantrópicos no Brasil no periodo de 2003-2010: uma análise do processo de implantação da contratualização. Brasília (DF): 2012.

Portaria Interministerial no 285/MEC/MS de 24 de março de 2015. Redefine o programa de certificação de Hospitais de Ensino. Disponível em: < http://bvsms.saude.gov.br/bvs/ saudelegis/gm/2015/prt0285_24_03_2015.html>. Acesso em: 06 jul. 2015.

. Secretaria de Atenção. Cadastro Nacional de Estabelecimentos de Saúde. Disponível em: < http://cnes.datasus.gov.br/Mod_Ind_hospitais_Ensino.asp >. Acesso em: 05 jul. 2016.

BRIZOLA, Jeremias Bequer. Gestão hospitalar: análise de desempenho de um hospital universitário e de ensino antes e após a contratualização com o sistema único de saúde. Dissertação (Mestrado em Saúde Coletiva) - Universidade Estadual de Londrina. Londrina (PR): 2010. 
CHARMAZ, K. A construçâo da teoria fundamentada: guia prático para análise qualitativa. Porto Alegre: Artmed; 2009.

DALlORA, M. E. L. V.; FOSTER, A. C. A importância da gestão de custos em hospitais de ensino: considerações teóricas. Rev. Med. (Ribeirão Preto), v. 41, n. 2, abr-jun, 2008. Disponível em: <http://www.hmtj.org.br/arquivos.hmtj/art_05.pdf >. Acesso em: 17 jul. 2015.

GALANTE, Anderson C.; COELHO, Marta Pazos Peralba; FIGUEIREDO, Florêncio; CARVALHO, Augusto. Implantação de método de gestão em hospitais de ensino no distrito federal. In: II Congresso Consad de Gestão Pública. Painel 38: tendências atuais na gestão de saúde. s/d.

GUBA, E. G.; LINCOLN, Y. S. Fourth Generation Evaluation. Newbury Park: SAGE Publications, 1989, 294 p.

LOBO, M. S. C. et al. Impacto da reforma de financiamento de hospitais de ensino no Brasil. Rev. Saúde Pública, n. 43, v. 3, p. 437-445, 2009. Disponível em: <http://www.scielo.br/scielo. php?script=sci_arttext\&pid=S0034-89102009000300007>. Acesso em: 31 mai. 2013.

. Avaliação de desempenho e integração docente-assistencial nos hospitais universitários. Rev. Saúde Pública, n. 44, v. 4, p. 581-590, 2010. Disponível em: <http://www.scielo.br/scielo. php?script=sci_arttext\&pid=S0034-89102010000400001>. Acesso em: 30 mai. 2013.

MACHADO, Sérgio Pinto; KUCHENBECKER, Ricardo. Desafios e perspectivas futuras dos hospitais universitários no Brasil. Ciência e Saúde Coletiva. v. 12, n. 4, p. 871-877. 2007.

PARPINELLI, Mary. A reforma do sistema da atenção hospitalar brasileira: o quê muda para o CAISM?. Serviço Social e Saúde. v. 4, n. 61, 2010. Disponível em: <https://www.researchgate. net/publication/309690257_A_reforma_do_sistema_da_atencao_hospitalar_brasileira_o_ que_muda_para_o_CAISM>. Acesso em: 19 mar. 2020. 


\section{Abstract}

\section{Impact of Restructuring Program of Teaching Hospitals in SUS in a Ceara hospital}

In order to evaluate the performance of a teaching hospital in the State of Ceará after its contracting with the Unified Health System, an evaluative, descriptive and exploratory research was conducted with a qualitative approach, based on the Fourth Generation Evaluation Guba and Lincoln (1989), in a philanthropic hospital located in the interior of the state of Ceará from November 2014 to May 2015. This research followed seven of the 12 steps proposed by the dialectical hermeneutic circle, having as subjects 33 respondents divided into groups: Stakeholders of Management, Stakeholders of Assistance, and Stakeholders of Teaching and Research. In order to analyze the data, the technique of constant comparison was used, through the Structured Data Theory, and it was evidenced that after the contracting with the Unified Health System, from the Restructuring Program of the Teaching Hospitals in Brazil, the hospital in this study, progress was made in relation to the three normative axes of teaching hospitals, with advances related to partnerships with Higher Education Institutions, the work of the Monitoring Committee, and the specific funding for contracting.

Keywords: Hospitals Teaching. Evaluation. Method. Health Services. 